\title{
Модернизация систем, регулирующих температуры поверхностей многослойных ограждающих конструкций
}

\section{Н. А. Прусенков}

Одесский национальный политехнический университет, пр. Шевченко, 1, г. Одесса, 65044, Украина

\begin{abstract}
Экономичность терморегуляцฺии многослойными ограждающими конструкциями (МОК) зданий и сооружений СНиП, действовавшие ранее в Украине, регламентировали установлением приемлемых в определенные периоды эксплуатации перепадов температур, декларируя неизменность удельных термических сопротивлений замкнутых составляющих, формирующих их. Такой подход исключает регулирование потерь при изменении температур в пространстве, окружающем МОК. Современная ДБН, декларируя перспективность учета потерь тепловой оболочкой здания (ТОЗ), остановилась на справочных рекомендациях (Додаток Н), учитывающих общий коэффициент теплопередачи, исключающий изменения потерь тепла в потоке, пересекающем МОК при эксплуатации. Компенсационные поступления тепла и утилизация выброса в подвижной среде указанными нормативами не предусматриваются. Перспектива модернизации существуюших замкнутых систем для регулирования потерь энергии МОК дополнением ее поступлениями в подвижных слоях, компенсирующим взаимодействием недостачу тепла в объединяемых энергетических потоках, очевидна, но сдерживается отсутствием нормативов, допускающих его. Целесообразно создание теоретического и законодательного утверждения в нормативе, предусматривающем взаимодействие в МОК систем из замкнутых и подвижных сред, для обеспечения регулирования потерь источниками энергии в потоках, их пересекающих.
\end{abstract}

Ключевые слова: Взаимодействие, Выброс, Замкнутый и подвижный слои, Переход тепловых потоков, Регулирование потерь, Система, Теплоноситель, Теплообмен, Тектология, Эволющия, Эксплуатационный режим.

\section{Модернізація систем, регулюючих температури поверхонь багатоша- рових конструкцій огорож}

\section{М. О. Прусенков}

Одеський національний політехнічний університет, пр.. Шевченка,1, м. Одеса, 65044, Україна

\begin{abstract}
Економічність терморегулячії багатошаровими конструкціями огорож будівель і споруд СНіП, щзо діяли раніше в Україні, регламентували встановленням прийнятних для певних періодів експлуатації перепадів температур, декларуючи незмінність питомих термічних опорів замкнутих складових, щуо формують їх. Такий підхід виключає регулювання втрат енергії при зміні температур в просторі, щзо оточує багатошарова конструкиія огорожі. Сучасна ДБН, декларуючи перспективність обліку втрат тепловою оболонкою будівлі (ТОБ), зупинилася на довідкових рекомендаціях, які враховують загальний коефіцієнт теплопередачі, щзо виключає облік втрат тепла в потоиі, який перетинає багатомарову конструкиію огорожі при експлуатації. Компенсаційні надходження тепла і утилізачія викиду в рухомому середовищі зазначеними нормативами не передбачена. Перспектива модернізації існуючих систем, для регулювання втрат енергї, доповненням їх надходженнями в рухомих шарах та компенсації їх взаємодією енергетичних струмів, очевидна, але стримується відсутністю сучасних нормативів, щзо допускають вказаний обмін. Доиільно створення теоретичного твердження, щзо передбачає взаємодію у багатошарових конструкціях огорожі систем з замкнутими і рухомими середовищами, які забезпечують регулювання втрат джерелами енергї потоків, щуо їх перетинають.
\end{abstract}

Ключеві слова: Взаємодія, Викид, Замкнений шар, Перехід струмів тепла, Шар, шуо рухає (рухомий шар), Регулювання втрат, Система,Теплоносій, Теплообмін, Тектологія, Еволючія, Експлуатаційний режим.

(C) The Author(s) 2018. This article is an open access publication

This work is licensed under the Creative Commons Attribution 4.0 International License (CC BY) http://creativecommons.org/licenses/by/4.0/

\section{1. Взаимодействие замкнутых и подвижных слоев МОК. Цель публикации.}

Конструирование и использование многослойных ограждающих конструкций (МОК) из замкнутых сред и материалов, обеспечивающих нормализацию перехода тепла между их внутренней и наружной поверхностя- ми, узаконены отечественными нормами в конце прошлого - начале текущего века [1,2]. Пересмотр свойств потоков и сред, формирующих подвижные слои МОК и способных регулировать затраты энергии на поддержание заданных температур поверхностей, обосновывает конструктивные и теоретические решения, позволяющие не только нормировать но и исключать потери 
тепла ими $[3,4,5]$. Возникающие противоречия требованиям действующих нормативных указаний устранимы взаимодействием существующих замкнутых слоев с подвижной средой [4-7].

Известные примеры нормирования энергии, переходящей через наружные поверхности оград в период эксплуатации, не имеют достаточного объема законодательных и нормативных обоснований, объясняющих и регламентирующих взаимодействие замкнутых и подвижных сред, для устранения потерь через поверхности слоев МОК. Цель публикации - обновление и дополнение числа направлений модернизации конструктивных и технологических особенностей МОК включением в их состав подвижных слоев, взаимодействующих с замкнутыми [6,7] для уменьшения и устранения выброса тепла (Qвыб.н, дж) через ее наружную поверхность.

Для систем, формирующих переход тепловым потоком МОК, состоящих исключительно из замкнутых сред, принципы взаимодействия потоков широко известны. Нормативные документы и стандартные методики расчетов определяют суммарные $\left(\mathrm{Q} \sum\right.$ пис.зам, дж) и составляющие их потери тепла

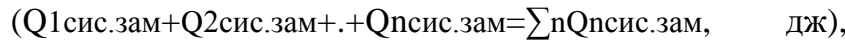
связывая их послойным сложением [1-5]:

$$
\begin{aligned}
& \mathrm{Q} \sum \text { псис.зам = Q1 сис.зам + Q2сис.зам +..... Qпсис.зам = } \\
& =\sum \mathrm{nQncис.зам}=\text { Qсис.1, дж }
\end{aligned}
$$

Поверхностями соприкосновения подвижных и замкнутых слоев разделяют (позиционируют) потери объединенной (совмещенной) системой взаимодействия (3) на слагаемые, связанные зависимо от [8-10]:

- поступлений тепла через внутреннюю поверхность соответствующего (n) замкнутого слоя (Q $\sum$ псис.зам == Qсис.1, дж (1)) из внутреннего окружающего пространства (Q1сис.зам, дж - см. (1)) и от предшествующего замкнутого (n-1) слоя или соприкасающегося с ним подвижного слоя (mx) (рис.1) [9,10];

- поступлений тепла из сред соответствующих подвижных (m) слоев, (Q $\Sigma$ тсис.под, дж), объединяемых в суммарные поступления в каждый подвижный слой

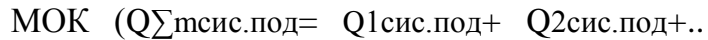

Qmсис.под, дж ) с учетом взаимодействия с поступлениями от наружной поверхности предшествующего этому подвижному (n - если он есть) замкнутого слоя, сложенных при теплообмене с затратами от источника энергии на перемещение подвижной среды в данном слое (m): (А $\sum$ тсис.под= А1сис.под+ + А2сис.под+...+ Атсис.под, дж ) - см. Рис.1[9,10]:

Q $\sum$ тсис.под=(Q1сис.под+...+Qтсис.под)+(А1сис.под+ ...+ $\mathrm{Amсис.под})=\left(\mathrm{Q} \sum\right.$ тсис.под+ $\mathrm{A} \sum$ тсис.под $)=$ $=\sum \mathrm{m}(\mathrm{Qmсис.под+Атсис.под})=\mathrm{Qcис.} 2$, дж

Для иллюстрирования модернизации МОК включением в ее конструкцию систем с подвижным слоем, выбран пример оценки взаимодействия двух из них, базирующийся на утверждении, что при равенстве температур соприкасающихся поверхностей, потерь тепла между ними нет [1-5] (Рис.1) [9,10]:

- первой (сис. $1=$ сис.зам) - замкнутой $(\delta$ вс $)$, узаконенной действующими нормами $[1-5,9,10]$, примыка- ющей к внутреннему пространству МОК и соприкасающейся с подвижным слоем, входящим во вторую систему (сис.2);

- второй (сис.2=сис.под) - включающей подвижный (пс) слой и состоящей из двух соприкасающихся подвижного и наружного слоев МОК $(\delta п \mathrm{n}+\delta$ нс):

1) одного подвижного слоя, с подвижной средой $(\delta п c)$, соприкасающегося с наружной (сис.1) и внутренней (сис.2) поверхностями внутреннего (сис.1) и наружного (сис.2) замкнутых слоев, составляющих системы и располагаемого между ними [6-10];

2) другого замкнутого слоя со средой $(\delta н \mathrm{c})$, соприкасающейся с наружной поверхностью (см. сис.2) подвижного слоя $(\delta п))$ и наружным пространством.

Дополнение принципов оценки и регулирования энергии, представленных публикацией для достижения цели, взаимодействием подвижной и замкнутой систем в условиях эксплуатации (1)+(2) прогнозирует создание объединенной эволюционной системы (3), регулирующей потери энергии и совершенствующей объединяемые системы устранением (онулением) выброса через наружную поверхность МОК (Qвыб.н=0, дж) [4,5,8 10].

В простейшем варианте определения общих затрат тепла взаимодействующими слоями, допустимо сложение их затрат ('пзам' или 'тпод'). Суммарные потери совмещенной системы (Q⿱宀с⿰ис.сум= Qсис.3, дж) группируются по конструктивным особенностям слоев на замкнутые и подвижные составляющие (Q $\sum$ псис.зам и $\mathrm{Q} \sum$ тсис.под, дж) МОК, с учетом основ тектологии и эксергии $[8,9]$ :

$\mathrm{Qmn} \sum$ сис.сум= Q $\sum$ псис.зам+ Q $\sum$ тсис.под=

= Qсис.1+Qсис.2= Qсис.3, дж

Примечания 1: а) Затраты энергии на перемещение подвижной среды в подвижном слое, создаваемые источником теплопоступлений (2), учитываются при конструировании взаимодействующих систем регулирования температур и теплопоступлений поверхностей МОК (1-3). Общепринято, что при пневмотранспорте их влияние на изменение теплотехнических характеристик взаимодействующих систем пренебрежимо мало. При оценке затрат энергии источниками объединяемых систем, суммарные потери тепла на обмен каждой из них формируют в общей подвижной среде [3-8]. Публикация сокращает число слагаемых, аккумулируя оценку поступлений тепла без затрат на перемещение подвижной среды (2) в суммарной системе (3). Потери на это в подвижном слое (2) фиксируются, но отдельно не рассматриваются, как известные в пневмотранспорте (2).

б) Принципы определения количества удаляемого тепла в среде подвижного слоя (Qуд.пс, дж) и его регулирование подчиняются закономерностям теплопереноса. Их определение выходит за рамки целей, декларированных публикацией, и в ней не рассмотрены. Целесообразно обособление оценки перспектив утилизации удаляемой части тепла в среде подвижного теплоносителя (Qуд.пс, дж) при использовании особенностей эксплуатации МОК в сооружении.

в) Взаимодействие теплопоступлений в среде каждого подвижного потока с теплом, поступающим в них 
через поверхности замкнутых, соприкасающихся с ним, осуществляется обычным теплообменом, регламентированным объединением теплосодержания с теплопоступлением в каждом слое. В рассмотренном примере (см. Рис.1 $[9,10])$, для иллюстрирования идеи публикации, предложен вариант, в котором теплопоступление источника сис.1 в сис.2 через наружную поверхность внутреннего слоя ( $\delta$ вс) исключено. Это обосновывает компенсацию выброса через наружный замкнутый слой $(\delta н с)$ поступлениями тепла исключительно от источника подвижного слоя (Qсис.2, дж - (2) и Рис. $1[9,10]$.$) ,$ устранением выбрасываемого избытка (Qвыб.н=0, дж) поступлений в наружный слой (ठнс) потоком тепла суммарной системы (Qсис.3, дж (3)).

\section{2. Конструктивные дополнения для устройства подвижного слоя МОК}

Достижение заявленной цели предложено осуществить модернизацией конструкции МОК следующими конструктивными и эксплуатационными изменениями см. Рис.1 [9,10,11]:

- Размещение подвижного теплового потока (Qсис.2, дж) с самостоятельно регулируемым источником энергии (сис.2) в слое с подвижной средой $(\delta п c)$, между существующими замкнутыми - наружным ( $\delta$ нс) и внутренним $(\delta \mathrm{Bc})$;

- Регулирование поступления, его температуры и расхода подвижного потока (Qсис.2= $\mathrm{f}(\mathrm{t})$, дж), зависимо от температуры наружного пространства (tн, $\left.{ }^{\circ} \mathrm{K}\right)$;

- Обеспечение уноса транспортирующей среды и избытка тепла за счет реализации энергетического потенциала составляющих системы (сис.2) - см.(2).

Примечание 2: В примере, предложенном публикацией (Рис.1 [9,10]), рассматривается упрощенный вариант регулирования теплопоступлений изменениями расхода $\left(\mathrm{L}, \mathrm{m}^{3} /\right.$ сек) и скорости $(\mathrm{V}, \mathrm{M} / \mathrm{c})$ теплоносителя в подвижной системе (сис.2 - Атсис.под - см.(2.)), что широко применяется системами пневмо- и гидротранспорта, исключая необходимость, для примера, конкретизации и описания особенностей расчета известных конструктивных элементов МОК;

- Применение подвижной среды с регулируемыми функциональными возможностями $\left(-\tau,{ }^{\circ} \mathrm{K}-\right.$ температура конденсации влаги; - $\varphi$, с - влажность, ..., исключенных из рассмотрения нормативами [1-5]), требует контроля и поддержания их расчетных значений. Этим объясняется ограничение минимумов температур поверхностей подвижного слоя требованием, исключающим конденсацию влаги $\left(\mathrm{t} п н>\tau_{\text {нп, }}{ }^{\circ} \mathrm{K}\right)$ и обосновываемым условиями эксплуатации МОК. Ограничение регулируемого минимума температуры на наружной поверхности подвижного слоя, регламентированное условиями эксплуатации МОК, следует считать обязательным конструктивным решением.

\section{3. Регламентирование температур на по- верхностях подвижного слоя}

Переход тепла между поверхностями подвижного

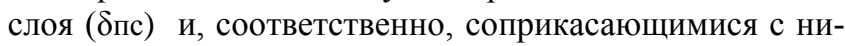
ми наружным $(\delta н \mathrm{c})$ и внутренним $(\delta \mathrm{Bc})$ замкнутым сло- ями ограждения регламентирован соотношением температур на их контактирующих поверхностях ( a так же tпн и tнп, ${ }^{\circ} \mathrm{K}$ ) при равенстве температур наружных поверхностей температурам соответствующих окружающих МОК наружного и внутреннего пространств (

В примере, базирующемся на общеизвестности методов регулирования температур в замкнутых слоях, примененном для соприкасающихся поверхностей, достижение цели публикации (Qвыб.н= 0, дж) обеспечено выполнением требований нормативно-законодательной базы теплотехники и термодинамики на этапе эксплуатации, при взаимодействии замкнутых с установленным между ними слоем с подвижной средой (рис.1) $[9,10]$.

Равенство температур соприкасающихся поверхностей, функционирующих систем, в слоях от разных источников, достигается отличающимися способами:

- tвп $=$ tпв, ${ }^{\circ} \mathrm{K}$ - равенство температур наружной поверхности внутреннего замкнутого слоя (tвп, $\left.{ }^{\circ} \mathrm{K}\right)$ и соприкасающейся с ней внутренней поверхности подвижного слоя (tпв, $\left.{ }^{\circ} \mathrm{K}\right)$ - обеспечивается одинаковостью температур на наружной поверхности внутреннего слоя (созданной в соответствии с законом Фурье) при постоянстве температуры теплопоступлений (tв= const, ${ }^{\circ} \mathrm{K}$ - согласно ДБН [1]) от источника исходной системы (сис.1) и удельных термических сопротивлений замкнутых слоев МОК, как и внутреннего (Ryд.3.=const, $\left.\left(\mathrm{M}^{2} \mathrm{x}^{0} \mathrm{~K}\right) / \mathrm{BT}\right)$, а с другой стороны - подачей теплопоступлений от регулирующего источника подвижной системы (сис.2) с постоянными температурой (tпc=tпв= const, $\left.{ }^{\circ} \mathrm{K}\right)$ и скоростью подвижной среды $(\mathrm{V} п$, м/сек), рассчитываемыми зависимо от температуры наружного пространства и теплосодержания, при регулируемой скорости этой среды в любой момент эксплуатации (tнф, $\left.{ }^{\circ} \mathrm{K}\right)$. В примере это равенство температур предотвращает переход тепла между внутренним $(\delta \mathrm{Bc})$ и подвижным (ठпс) слоями, упрощая определение результатов взаимодействия пересекающихся потоков. Решение этой задачи при неравенстве указанных температур известно, но усложняет пояснение достижимости цели и в публикации не представлено;

tпн= tнп, ${ }^{\circ} \mathrm{K}$ - равенство температуры наружной поверхности подвижного слоя (tпн, $\left.{ }^{\circ} \mathrm{K}\right)$, соприкасающейся с внутренней поверхностью наружного замкнутого слоя MOK (tнп, $\left.{ }^{\circ} \mathrm{K}\right)$, температуре внутренней поверхности этого наружного слоя, соприкасающейся с наружной поверхностью подвижного слоя ( $\left.\mathrm{t} н=\mathrm{t} н п,{ }^{\circ} \mathrm{K}\right)$ - устанавливается регулированием, зависимо от фактических значений температуры наружного пространства $\left(\mathrm{t}=\mathrm{t} \phi \phi,{ }^{\circ} \mathrm{K}\right)$ в период эксплуатации. Для этого изменяют скорость подвижной среды (Vпс, м/сек) в подвижной системе (сис.2) при неизменной температуре поступлений $\left(\mathrm{t} п \mathrm{c}=\mathrm{t} п \mathrm{~B}=\mathrm{const},{ }^{\circ} \mathrm{K}\right)$ и постоянстве температуры внутреннего пространства MOK ( $\mathrm{t}_{\mathrm{B}}=$ const, $\left.{ }^{\mathrm{O}} \mathrm{K}\right)$ при неизменных удельных термических сопротивлениях замкнутых слоев $\left(\right.$ Ryд.x $=$ const, $\left.\left(\mathrm{M}^{2} \mathrm{x} \mathrm{K}\right) / \mathrm{BT}\right)$. Этим обеспечивают уравнивание фактических температур наружной поверхности наружного замкнутого слоя и в окружающем пространстве снаружи МОК (tнф= tннф, $\left.{ }^{\circ} \mathrm{K}\right)$.

При изменениях температур на поверхностях подвижного слоя следует пересматривать значения и возможные изменения потерь энергии отдельными состав- 
ляющими объединяемых систем и всей конструкцией при эксплуатации.

Действующими нормативной и теоретической базами [1-9] изменения теплопоступлений, теплосодержаний, скоростей и расходов в замкнутых средах не предусмотрены. Используемый в ДБН [1] теоретикопрактический арсенал теплотехники позволяет рассчитать параметры потока и среды в подвижном слое МОК только в константном режиме для замкнутых слоев MOK (Qуд.пс $=0$, дж; $\Delta \mathrm{tx}==$ const, ${ }^{\circ} \mathrm{K} ; \mathrm{V}_{п \mathrm{c}}=0, \mathrm{M} /$ сек $)$.

Примечание 3: Допущенное упрощение изменений температурного режима в публикации не загромождает объяснение способа достижения ее цели учетом решений известных задач. При этом, не следует забывать об обязательности затрат подвижной системой (сис.2) на перемещение среды, регламентирующих тепловой поток в этой системе (Qсис.2, дж, см.ф.3 ), скорость (Vпс, м/сек) и, соответственно, температуры внутренней и наружной поверхностей подвижного слоя (тпв и tпн, $\left.{ }^{\circ} \mathrm{K}\right)$, а так же о средней температуре среды в подвижном слое (tср.уд, $\left.{ }^{\circ} \mathrm{K}\right)$, регламентирующей унос (удаление) тепла (Qуд.пс, дж) из системы - см. Рис.1 $[9,10]$.

\section{Выводы}

1. Оптимизация затрат тепла в потоках, пересекающих замкнутые слои МОК, опирается на принципы послойного позиционирования и суммирования их характеристик в константном режиме, выполняя закона Фурье. Это ограничивает потери тепла ограждениями, установлением допустимых интервалов параметров.

2. Декларирование постоянства температуры внутренней поверхности МОК, приравниваемой температуре воздушного пространства внутри конструкции, соответствует допустимости ограничений, узаконенных нормами $[1,2]$.

3. Перспективно регулирование температур поверхностей МОК, вплоть до выполнения ими функций отопительных приборов, но при условии исключения потерь тепла в окружающее пространство, ухудшающего ТЭП МОК.

4. Для упрощения формирования теоретической базы модернизации МОК привлечением свойств

подвижной среды, в примере (Рис.1[9,10]) рассмотрена конструкция с минимальным числом слоев, при наличии подвижного.

5. Совместное решение уравнений (1) - (3), учитывающее уточнение особенностей технологии эксплуатации МОК с подвижным слоем, воплощает принципы создания модернизированной системы более высокого уровня, сформированной взаимодействием представ- ленных систем для перемещения тепла и транспорта среды с указанными свойствами.

6. В результате тектологического взаимодействия замкнутой, узаконенной действующими нормативами системы перехода МОК тепловым потоком (сис.1) и подвижной, работающей аналогично пневмотранспортным системам (сис.2), создается модернизированная система регулирования потерь тепла потоком, пересекающим поверхности слоев ограждения в период эксплуатации (сис.3). Она (сис.3) проявляет свойства, отсутствующие у взаимодействующих систем (сис.1 и сис.2), и исключает потери тепла через наружную поверхность МОК.

\section{Литература}

1. ДБН В.2.6-31:2006 тепловая изоляция зданий. - К.: Минстрой Украины, Укрархстройинформ, 2006. - 64 с., ил.

2. СНиП II-3-79** Гл.3 Строительная теплотехника М.: Госстрой СССР, 1986. - 32c.

3. Тихомиров К.В. теплотехника, тепло-газоснабжение и вентиляция. - М.: Стройиздат, 1981, 272 с., ил.

4. Соколов Е.Я., Бородянский В.М. энергети-ческие основы трансформации тепла и процессов охлаждения. - М.: Энергоиздат, 1981. - 320 с., ил.

5. Егорушкин В. Е., Цеплович Б. И. Основы гидравлики и теплотехники. - М.: Машиностроение, 1981. - 268 с., ил.

6. Прусенков Н.А. Компенсация потерь тепла в 'подвижном’ слое.- Одесса: ОНАХТ, Холодильная техника и технология, №1(135), 2012.- ст.46-49.

7. Прусенков Н.А. Предпосылки учета особенностей перехода тепловым потоком ограждений с 'подвижным’ слоем. - Одесса: ОГАСА, Вестник ОГАСА, №50, ч. 1, 2013. - ст. 251-255.

8. Прусенков Н.А. Использование принципов тектологии для регулирования потерь тепла потоками. - Одесса: ОНПУ, Пути реализации кредитно-модульной системы, №10, 2015. - ст. 58 - 63 .

9. Прусенков Н.А. Взаимодействие систем теплоснабжения для устранения потерь наружной поверхностью МОК. - Одесса: ОНАХТ, Холодильная техника и технология №6(152), 2017. - cm. 35-40.

10.Прусенков Н.А. Схема определения составляющих потерь тепла в подвижном слое МОК. - Одесса: ОНАХТ, Холодильная техника и технология, №5 (151), 2014.- ст.55-60.

Отримана в редакції 06.02.2018, прийнята до друку 06.03.2018

\section{Modernization of the systems regulating the temperatures of the multi- layered enclosing structure surfaces}

\section{N. A. Prusenkov}

Odessa National Polytechnic University, av. Shevchenko, 1, Odessa, 65044, Ukraine

The efficiency of thermoregulation by multilayered enclosing structures (MES) of buildings and structures by SNiP, which previously existed in Ukraine, was regulated by establishing temperature drops acceptable during certain periods of operation, declaring the invariance of specific thermal resistances of the closed components forming them. This 
approach eliminates the regulation of losses at temperature changes in the space surrounding the MES. Modern SBN, declaring the prospect of accounting for the losses of the thermal envelope of the building (TEB), focused on reference recommendations (Appendix $H$ ), taking into account the overall heat transfer coefficient, excluding changes in heat loss in the flow crossing the MES during operation. Compensatory heat input and disposal of emissions in a mobile environment are not provided by the specified standards. The prospect of existing closed systems upgrading to control MES energy losses by supplementing its income in moving layers, compensating the lack of heat in the combined energy flows, is obvious, but is hampered by the lack of standards that allow it. It is advisable to create a theoretical and legislative statement in the Regulation providing for the interaction of systems from closed and mobile environments in the MES to ensure the regulation of losses by energy sources in the flows crossing them.

Keywords: Interaction, Emission, Closed and mobile layers, Heat flow transfer, Losses regulation, System, Heat transfer medium, Heat exchange, Tectology, Evolution, Operational mode.

\section{References}

1. DBN B. 2.6-31:2006 - (ZMINY-13) Teplovaya izolyatsiya zdaniy $i$ sooruzheny. K: Minstroy Ukrainy "Ukrstroyinform”, 2014, 65p., s. il. (in Ukrainian)

2. SNiP II-3-79** (1986) Stroitelnay teplotehnika. M.: Gosstroy, 32p., s. il. (in Russian)

3. Tihomsrov K.V. (1981) Typlotekhnika, typlogazosnabzhenie $i$ ventiliatsia. M: Stroyizdat, 272st. s.il. (in Russian) 4. Sokolov E.Y., Borodianskii V.M. (1981). Energeticheskie osnovy trunsformatsii tepla $i$ protscessov okhlazhdeniia. M.: Energoizdat, 320p., s. il (in Russian)

5. EgorushkinV.E., Ceplovich B.I. (1981) Osnovu gidravliki i teplotehniki. M: Mashinostroyniy, 268p.,s il. (in Russian)

6. Prusenkov N.A. (2012) Heat loss compensation in "mobile" potection layer. Odessa: ODAH, Refrigeration engineering and technology, 1(135), 46-48p. (in Russian)

7. Prusenkov N.A. (2013) Pryedposulki uchota osobenostyi perehoda teplovum potokom ograzhdeniy s podvizhnum sloyem. Odessa: OGASA, Vesnik OGASA, №50, ch.1, p. 251-255. (in Russian)

8. Prusenkov N.A. (2015) Ispol'zovaniye principov tektologiyi dly regulirovaniy poter' tepla potokami v MOK. Odessa: ONPU, Puti realizacii kreditno-modul'noy systemu, №10, 58-63p. (in Russian)

9. Prusenkov N.A. (2017) Vzaivmodeystvie system teplosnabzganiy dly ustraneniy poter' naruzgnoy poveyrhnost'y MOC. Odessa: ODAH, Refrigeration engineering and technology, 6(152), 36-42p. s il. (in Russian)

10. PrusenkovN.A. (2014) Shema opredeleniye sostavlyayuschih poter tepla v podvizhnom sloye MOK. Odessa: ODAH, Holodilnaya tehnika $i$ tehnologiya, №5(151), p. 55-60p. (in Russian)
Received 06 February 2018 Approved 06 March 2018 Available in Internet 30 April 2018 